Abstract

\title{
Sugar Sweetened Beverage Consumption in Auckland Primary School Children ${ }^{\dagger}$
}

\author{
Emma Smirk ${ }^{1}$, Cathryn Conlon ${ }^{2}$, Kathryn Beck ${ }^{2}$, Cheryl Gammon ${ }^{3}$ and Pamela von Hurst 2,* \\ 1 School of Sport, Exercise and Nutrition, Massey University, Auckland 0632, New Zealand; \\ emma.smirk@hotmail.com \\ 2 School of Sport, Exercise and Nutrition, College of Health, Massey University, Auckland 0632, \\ New Zealand; c.conlon@massey.ac.nz (C.C.); k.l.beck@massey.ac.nz (K.B.) \\ 3 College of Health, School of Health Sciences, Massey University, Auckland 0632, New Zealand; \\ c.gammon@massey.ac.nz \\ * Correspondence: P.R.vonHurst@massey.ac.nz \\ † Presented at the 2018 Nutrition Society of New Zealand Annual Conference, Auckland, New Zealand, \\ 28-30 November 2018.
}

Published: 12 March 2019

Background: Sugar sweetened beverage (SSB) consumption has a positive relationship with unhealthy weight gain in children. Due to the high childhood obesity rates in New Zealand (NZ), many schools have become 'water-only' schools (WOS) to try to decrease SSB consumption. However, the most recent comprehensive NZ beverage consumption statistics were published 15 years ago in 2003. The aim of this study was to investigate beverage consumption in 8 to 12 year old Auckland primary school children.

Methods: This cross-sectional study evaluated beverage consumption using a self-administered questionnaire. Body composition was measured using bioelectrical impedance analysis (BIA).

Results: Children ( $n=695,9.87 \pm 0.71$ years, $44.8 \%$ male) were recruited from 6 schools ( 4 WOS). Plain water was consumed $5+$ times per week by $93.1 \%$ of the children. Only $45.3 \%$ of the children consumed plain milk more than once per day and $16.4 \%$ consumed plain milk less than once per week. Flavoured milk was consumed by $6 \%$ of children $5+$ times per week. Soft drink and juice were consumed more than once per week by $30.6 \%$ and $39 \%$, respectively. Energy drinks and sports drinks were consumed never/less than once per week by $97.9 \%$ and $93.5 \%$, respectively. Children from WOS consumed significantly more flavoured milk, flavoured powdered milk, powdered fruit drink, fruit drink concentrate/cordial, soft drink, and tea than children from non-WOS. A positive relationship was found between consumption of all beverages and home availability, with an increased likelihood of consuming beverages $5+$ times per week if they were usually available at home. Soft drink consumption had a significant positive relationship with body fat percentage.

Conclusions: Water consumption was adequate but an unfavourable percentage of children consumed milk never/less than once a week. Parents limiting SSB home availability may contribute to a decreased consumption in children. Limiting soft drink consumption may help children achieve a healthy body fat percentage.

Supplementary Material: The poster is available online at www.mdpi.com/2504-3900/8/1/34/s1.

(C) 2019 by the authors. Licensee MDPI, Basel, Switzerland. This article is an open access article distributed under the terms and conditions of the Creative Commons Attribution (CC BY) license (http://creativecommons.org/licenses/by/4.0/). 